\title{
MAKING VIRTUAL CLASSROOMS OF GOOGLE PLATFORM MORE REAL USING TRANSPARENT INTERACTIVE SCREEN-BOARD (tiSb-Albania)
}

\author{
Romeo Teneqexhi ${ }^{1}$ and Loreta Kuneshka ${ }^{2}$ \\ ${ }^{I}$ Director of Distance Education Centre, Polytechnic University of Tirana, Albania, Sheshi "Nënë Tereza", \\ No 4. Tirana, Albania \\ ${ }^{2}$ Lecturer of Statistics, Medical University of Tirana, Albania, Rruga e Dibres, Tirana, Albania
}

\begin{abstract}
Virtual \& Real Face to Face teaching (Teneqexhi, \& Kuneshka, 2016) infrastructure, presented in $10^{\text {Th }}$ international conference of e-learning organized by IADIS, Madeira 2016, is improved now very much. We have baptized this new infrastructure "transparent interactive Screen-board (tiSb-Albania). Transparent interactive Screen-board is now easy implementable in traditional classrooms. The new feature of ex Screen-board is the interactivity. The interaction is done by using e-beam edge tool which comes with very interesting software for organizing lecture materials. We use e-beam tool in a very special way making lessons much more interesting. The teacher never shows his back to the students because the transparent board is between him and the students. We can write on Screen-board with normal markers (and erase by eraser) or with electronic ones (and erase electronically). Using our system it is possible to add new notes on board images (written by normal markers) even if they are already erased with the eraser. Thanks to e-beam software ${ }^{1}$ it is not necessary for the students to kip notes. Everything written by the teacher on the screen-board or showed in prepared slides are automatically saved in student's smart phone. So student can have forever "in his/her pocket" all the lectures in video form (stored in YouTube or somewhere else) and notes in slides form. The lessons organized with tiSb-Albania which are recorded can be transmitted live stream on the internet. So the number of students is not limited by the size of the classroom. Every student can follow live lessons being in the classroom or from home having the possibility to ask question and write on the screen-board if the teacher "gives" him the "chalk" to write on the screen-board. This is the idea of a "Mix Classroom". So mix classroom is a combination between traditional face to face teaching and e-learning. We have successfully experimented this kind of classroom teaching "Basic Circuit Theory" subject in Polytechnic University of Tirana. We also have experimented doing video based on real lecture's notices without using video camera. Every teacher can do it using nowadays smart phones. For the near future Polytechnic University of Tirana is planning to have common classes with Pristina University in Kosovo. In this way twin classes in different universities can have common lessons (even exams) in the same time with the same teacher. Virtual classroom of Google platform ${ }^{2}$ is perfect for organizing mix classrooms. Among other teaching materials for students used during lectures, we upload all recorded lessons in Google platform and every student can see real recorded lessons whenever he wants.
\end{abstract}

\section{KEYWORDS}

Virtual and Real Face To Face (VRFF) Teaching, Transparent Interactive Screen-Board (tiSb), Mix Classroom, Twin Classes, Preliminary Exam At Home Without Limitation in Time

\section{WHY RECORDING REAL LECTURES?}

Nowadays it is a pity doing a 50 or 100 minutes lecture and "erasing" at the end everything what is written (and said) on the black board. Historically students use to take notes during lecture most of the time not 100\% focused on what teacher says but not to lose or wrong copy anything from the blackboard. Nowadays a lot of students do by them self pictures of the blackboard or record audio using different audio recorders for future use at home during studding. I think it is teacher's duty to make students more focused on the lecture than the notes in their own notebooks. This is why we are working on recording real lectures in different ways.

\footnotetext{
${ }^{1} \mathrm{http}: / /$ www.classroom.google.com - Google platform for virtual classrooms

${ }^{2} \mathrm{http} / /$ www.e-beam.com/education/ebeam-edge/overview.html
} 


\section{VIRTUAL \& REAL FACE TO FACE AND “tiSb” INFRASTRUCTURE}

Virtual \& Real Face to Face teaching infrastructure, presented in $10^{\text {Th }}$ international conference of e-learning organized by IADIS, Madeira 2016, is improved now very much. In old infrastructure we needed: 1) two environments one for the teacher with a small number of students (Figure 1.a/b), and the big classroom for the rest of the students (Figure 2.a/b), 2) a sophisticated audio system for communication with most of the students in big classroom, 3) video system for the teacher to see and communicate with his students in the big classroom, 4) video switcher (blue box on desk Figure 1.a) used by the teacher, 5) a TV \& mirror system (TV in front of a big mirror and the students between TV and mirror) for the students in teacher's room for image flipping purpose (Figure 1.a TV behind the students, Figure 1.b mirror in front of students), 6) post production process for including computer graphics in final video lecture. This relatively complicated infrastructure is impossible to be widely use, so we have simplify this infrastructure and improved the features of our system involving in a very spatial way the well known "e-beam edge" tool produced by Luida 2 .
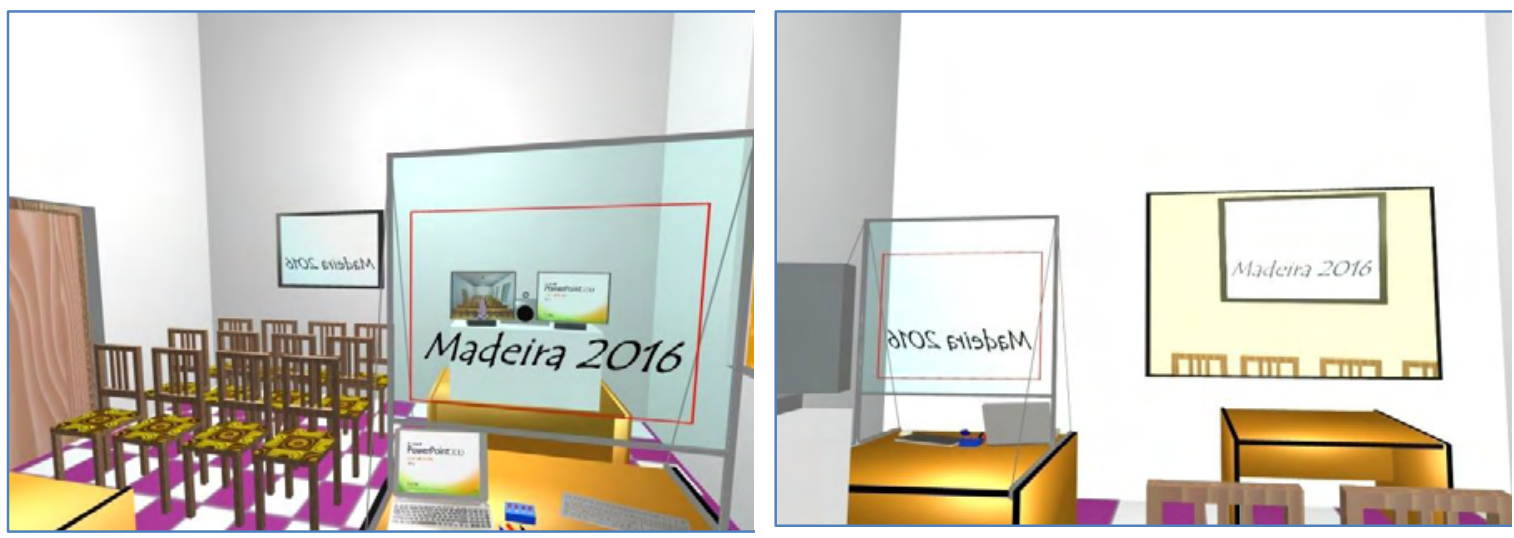

Figure $1 \mathrm{a} / \mathrm{b}$. In teacher's office. Teacher's (a) and student's (b) point of wiev in old VRFF infrastructure
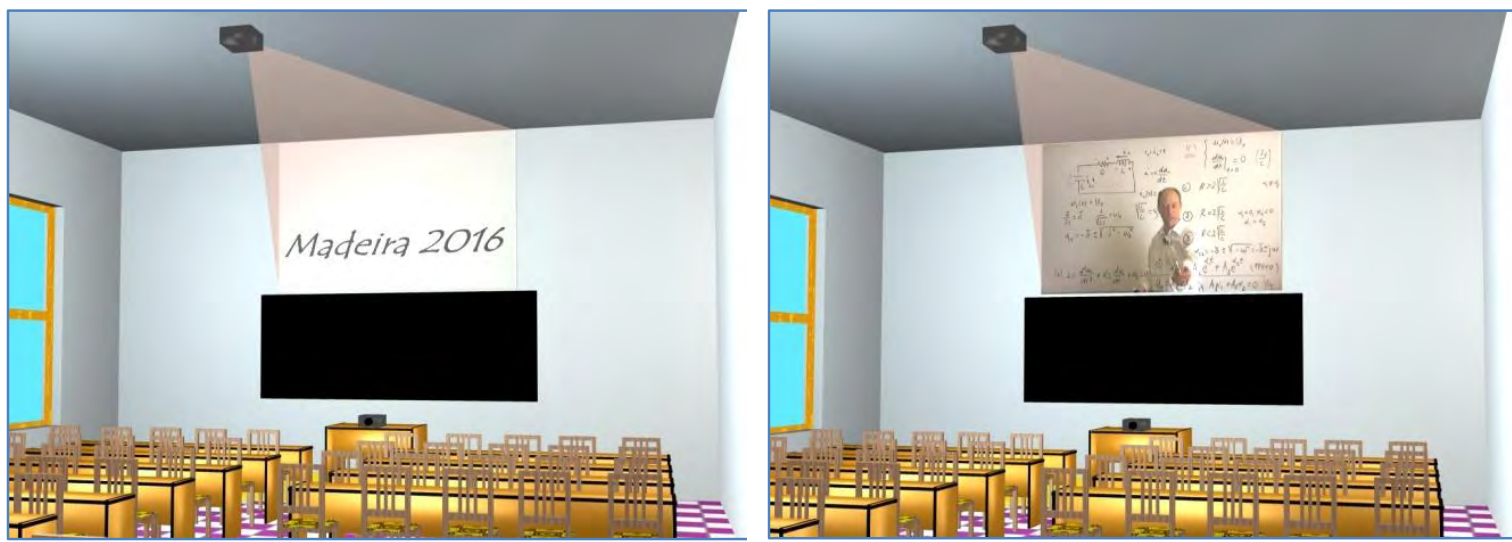

Figure $2 \mathrm{a} / \mathrm{b}$. In big classroom. Student's point of wiev in old VRFF infrastructure

The most important features of our system are the interaction using e-beam tool and live mixing of images taken from web camera in front of transparent board and computer screen. The new system we are representing here excludes all elements mention above (point 1 to 6 ). No more need for post production processes. We have baptized this new infrastructure "transparent interactive Screen-board" (tiSb-Albania). Transparent interactive Screen-board is easy implementable in traditional classrooms (Figure $3 \mathrm{a} / \mathrm{b}$ ). The teacher now is in the same classroom with the students. They can communicate without any problem like in every classroom. The only thing witch make the difference is the fact that students see the teacher, in a way virtually, via video projector (Figure 3b), of course bigger then normally. In fact the teacher is not virtually in the classroom. He is behind the white curtain at the corner of the classroom. The white curtain has two reasons to be there. First it creates 
a white background necessary for the teacher to see what he writes on the transparent board and second because for the student everything is written on the transparent board is left side right so it is unreadable in a way. In Figure 3a, on the left side of transparent board you see the e-beam tool incorporated in our system.
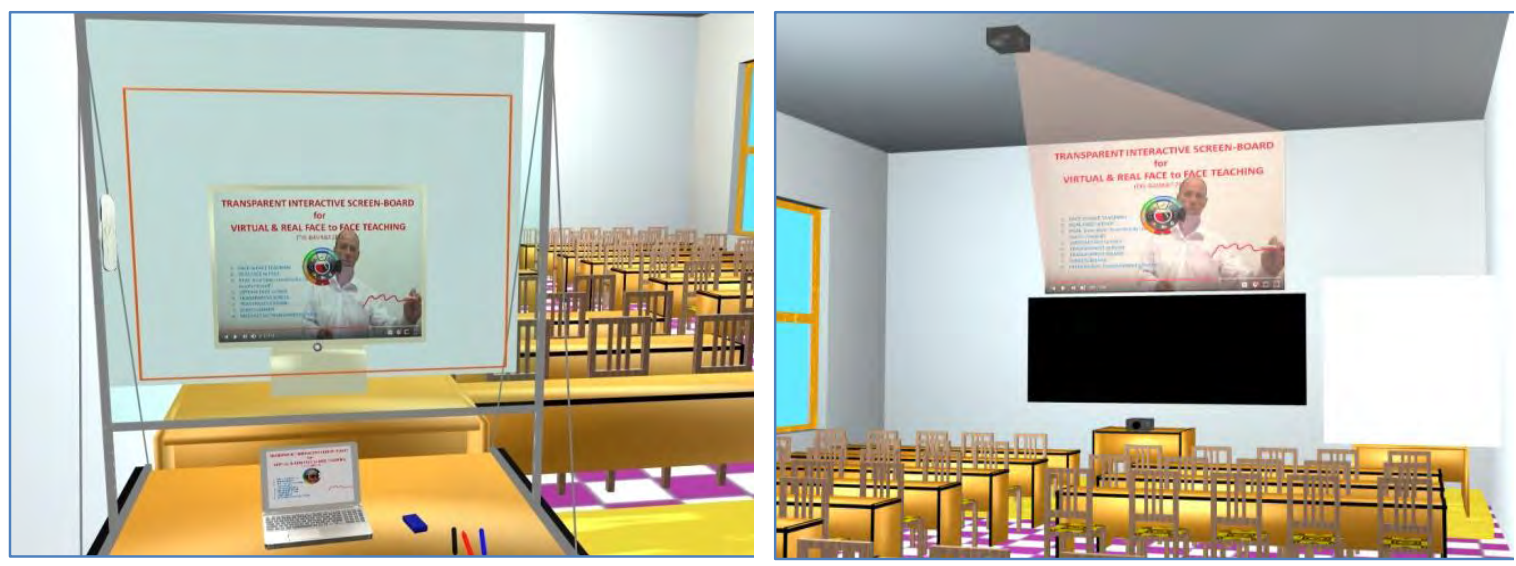

Figure 3 a/b. Teacher's (a) and (b) student's point of wiev in traditional classroom equipped with "tiSb"

\section{PRODUCING VIDEO OF REAL LECTURE WITHOUT USING VIDEO CAMERA}

We have successfully experimented another way for making video lectures without using any special infrastructure. In Figure $4 \mathrm{a} / \mathrm{b}$ there are pictures of traditional black boards taken by the teacher using his smart phone. At the beginning of the lecture teacher starts audio recording of his voice using an audio recording application in his smart phone. During the lecture teacher keeps his phone in a pocket of his shirt to record audio in good quality. After the lecture, teacher uploads black board's pictures and corresponding audio files in Google Drive. So students can see and listen real material of real lecture whenever he / she wants. But in this case it is a little bit difficult to listen audio from real lecture and understand which part of the notices the teacher is (was) writing in this moment.
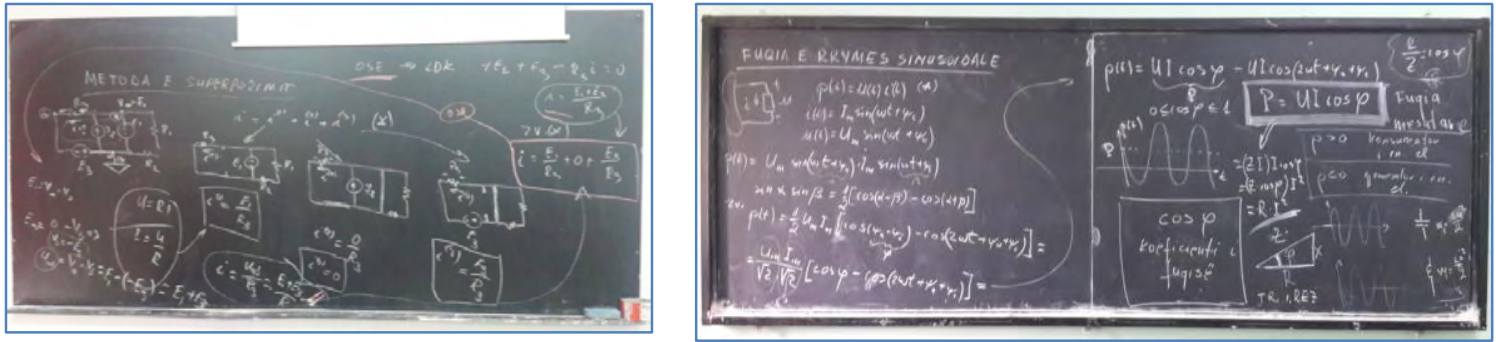

Figure $4 \mathrm{a} / \mathrm{b}$. Notes of a real lecture with associated audio uploaded in Google Classroom

This handicap can be eliminated by producing a true video using audio with teacher voice and the picture taken from the black board or last frame of any existing video of a good teacher on You Tube or some were else. But this kind of video needs a post production process and video editing. In Figure 5 the area more lighted in the picture is part of black board already written up to the corresponding time code. 


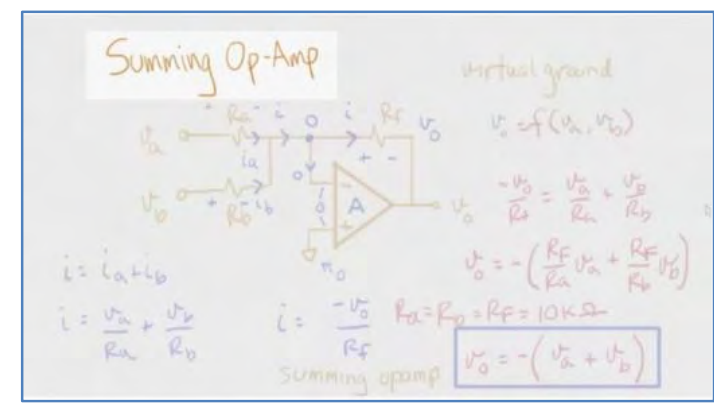

Time code: 00:00:10

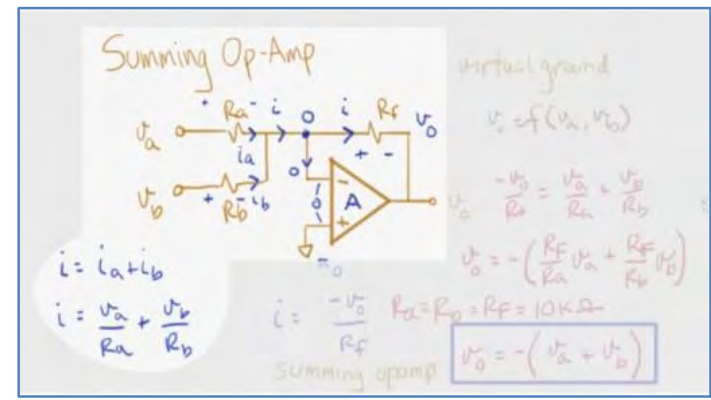

Time code: 00:05:11

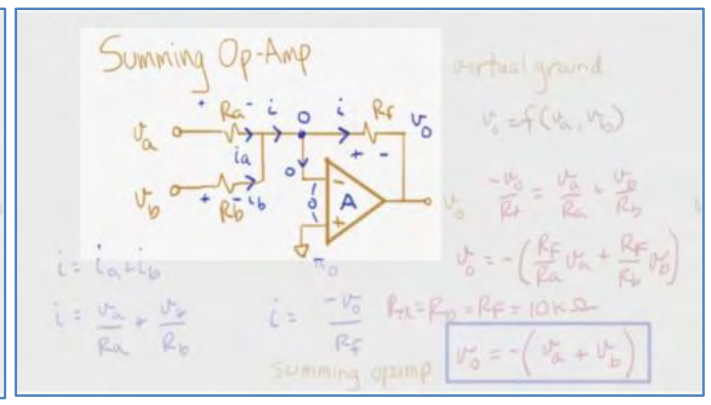

Time code: 00:01:20

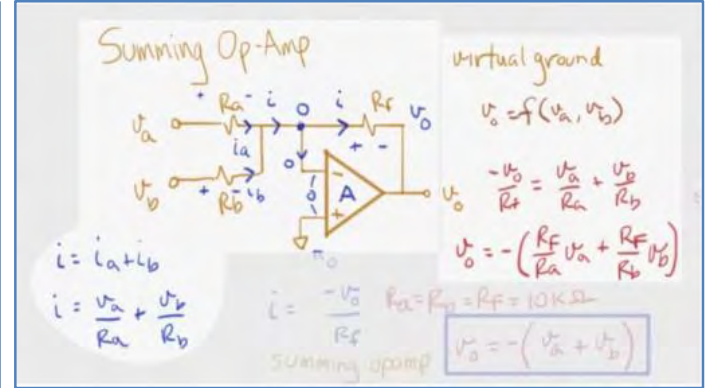

Time code: 00:07:45

Figure 5. Video lecture generated using just a final frame of a video lecture taken from YouTube ${ }^{3}$

Using virtual Classroom of Google platform we organize some kind of preliminary exams at home (before final exam) without limitation in time "forcing" students to get all the points of the test trying as many time as they need to do that. A considerable number of questions in this test are pieces of my video lecture (some seconds). To get the points of questions students must see the entire lecture to find out the right answer.

\section{FINAL DECLARATION}

Students of the future will be students without notebooks but not a single lost notice on the black board during all the period of studying in university. I still feel nostalgia for my studding time in university when I find any old notebook. Pages of these notes are becoming more and more yellow during the time pass. Nowadays notices in the smart phone never get yellow. We are lucky generation.

\section{REFERENCES}

Teneqexhi, R. Kuneshka, L. (2016). Virtual \& Real Face to Face Teaching. In MCCSIS 2016, 1-4 July, Madeira, Portugal ISBN: 978-989-8533-51-7, pp. 227-230.

http://www.classroom.google.com - Google platform for virtual classrooms

http://www.e-beam.com/education/ebeam-edge/overview.html

https://www.youtube.com/playlist?list=PLzUN9-WgjT3PcvDFD5cI9COE9E53CrcgA

\footnotetext{
${ }^{3}$ https://www.youtube.com/playlist?list=PLzUN9-WgjT3PcvDFD5cI9COE9E53CrcgA
} 